\title{
Surface Modification of Microcporous of Polycaprolactone (PCL) Microcarrier to Improve Microcarrier Biocompatibility
}

\author{
Nurhusna Samsudin ${ }^{1}$, Yumi Z. H-Y. Hashim ${ }^{1}$, Mohd A. Arifin ${ }^{2}$, Hamzah M. Salleh ${ }^{1}$ \\ ${ }^{1}$ International Institute for Halal Research and Training (INHART), International Islamic University Malaysia, Jalan Gombak, \\ 53100 Kuala Lumpur, Malaysia. \\ E-mail:nurhusna.samsudin@gmail.com,yumi@iium.edu.my \\ Corresponding authors e-mail: hamzah@iium.edu.my \\ ${ }^{2}$ Faculty of Engineering Technology, University Malaysia Pahang, Lebuhraya Tun Razak, 26300 Gambang, Kuantan, Pahang, Malaysia \\ E-mail:mazmir@ump.edu.my
}

\begin{abstract}
Oil/water emulsion solvent evaporation method was employed to fabricate polycaprolactone (PCL) microcarriers. In order to produce porous microcarrier, the method was slightly modified. The porous network channels were generated inside the microcarrier by introducing camphene that was dissolved in the same solvent used to dissolve raw PCL. The evaporation of solvent and sublimination of camphene during the process of emulsion solvent evaporation method, produce solidified porous microcarrier beads. The surface porous microcarriers beads were further modified to make it competent for cell attachment and proliferation. The surface of these microcarriers were modified with $\mathrm{UV} / \mathrm{O}_{3}$ system to introduce functional group and charge on the surface. The treatment followed with the immobilization of halal gelatin on the surface to imorove the biocompatibility of the microcarrier. Porous microcarrier with optimal size distribution was successfully fabricated. The average pore size of $11.74 \pm 8.32 \mu \mathrm{m}$ was obtained with the concentration of $20 \%$ (w/v) of camphene. The porous PCL microcarrier was further tailored with gelatin through surface treatment with $\mathrm{UV} / \mathrm{O}_{3}$ system and gelatin immobilization and validation of its compatibility towards mammalian cell was tested with cultivation of green monkyer kidney cell (Vero) in the suspension culture. Vero cells attach and proliferatie well on the gelatin coated porous PCL microcarrier with maximum cell number of $3.90 \times 10^{5}$ cells $/ \mathrm{ml}$ as compared to cell proliferation on $\mathrm{UV} / \mathrm{O}_{3}$ treated porous PCL microcarrier (1.83 $\times 10^{5}$ cells $/ \mathrm{ml}$ ). The developed microcarrier may be potentially applicable as a cell delivery scaffold for cell tissue culture and tissue engineering application.
\end{abstract}

Keywords - Halal; porous microcarrier; $\mathrm{UV} / \mathrm{O}_{3}$ treatment; microcarrier cell culture.

\section{INTRODUCTION}

The chemical composition of microcarrier such as properly tailored surface chemistry (functional group or macrobiomolecules) can improve the biological reaction of mammalian cell towards microcarrier. The physical characteristic of microcarrier such as size, surface charge, density and stability are significant to determine the cell behavior and response (cell adhesion rate, population, differentiation and maintenance) [1].

Porous microcarrier has a large surface to volume ratio for adhesion dependent cells. Porous microcarrier can be prepared by needle/tubing microfluidic device [2], combination of gas foaming and emulsion/solvent evaporation [3], microfluid technology [4] and an oil/water $(\mathrm{O} / \mathrm{W})$ emulsion solvent evaporation with porogen [1]. The oil/water $(\mathrm{O} / \mathrm{W})$ emulsion solvent evaporation is a very attractive method to fabricate porous microcarrier due to its convenience which requires only mild conditions such as ambient temperature and constant stirring to afford stable emulsions with narrow distribution [5]. In the presence of non-toxic porogen such as camphene pore channel within polymeric materials can be generated. Camphene easily dissolves in dichloromethane and solidifies at temperature below $40{ }^{\circ} \mathrm{C}$ leading to phase separation of camphene and polymeric materials [1]. The extraction of dichloromethane during solvent evaporation method is believed to facilitate the solification process of polymeric mixture and campne mixture. During the solification process, the polymer matrix and camphene are separated as the camphene part sublime thus, leaving a porous structure within the polymer microspheres.

In the current work, porous polycaprolactone (PCL) microcarriers were generated by introducing camphene 
porogen in PCL microspheres that were subjected to $\mathrm{UV} / \mathrm{O}_{3}$ treatment before gelatin immobilization on the surface. The fabricated porous microcarrier was preliminary evaluated with Vero cell.

\section{MAterials And MethodS}

\section{A. Materials}

Polycaprolactone (PCL) $(\mathrm{MW}=45,000)$ in pellet form, dichloromethane and poly(vinyl alcohol) (PVA) were supplied by Sigma-Aldrich (USA). Pure oxygen (>99\%; Linde Malaysia Sdn. Bhd), phosphate buffer (EMD Chemical Inc. USA), absolute ethanol (HmbG Chemicals, Germany) were used for sterility. Bovine gelatin was purchased from Halagel (Malaysia). Olive oil was obtained from a local hypermarket. Powder form of Dulbecco's modification of eagle's medium (DMEM), antibiotics (100 $\mathrm{U} / \mathrm{ml}$ penicillin, $0.1 \mathrm{~g} / \mathrm{l}$ streptomycin) and fetal bovine serum (FBS) were supplied by Gibco (USA). Accutase was purchased from Innovative Cell Technologies (USA). Sodium hydroxide, sodium bicarbonate and trypan blue were supplied by Sigma-Aldrich (USA). Ethyl acetate, silicone oil, $\mathrm{N}$-hydroxysuccinimide (NHS) and camphene from Merck Millipore (Germany). 1- ethyl-3-(3-dimethylaminopropyl)carbodiimide hydrochloride (EDAC) and 2-(Nmorpholino)ethanesulfonic acid (MES) were obtained from EMD Chemical Inc. (USA).

\section{B. Microcarrier preparation}

The preparation of microcarrier was achieved by a solvent evaporation method $[6,7]$ with slight modifications [8]. PCL (20-wt $\%$ ) was dissolved in dichloromethane. Camphene was dissolved separately in a container at $10 \%(\mathrm{w} / \mathrm{v})$. After both compounds had completely dissolved, both mixture were incorporated and stirred for 3 hours. The mixture were added dropwise into a $1.5 \%(\mathrm{w} / \mathrm{v})$ PVA reservoir (continuous phase). The resulting emulsion was stirred consecutively for 6 hours at room. The generated microcarriers were attained and washed with distilled water prior to drying overnight at $50{ }^{\circ} \mathrm{C}$.

\section{Surface treatment}

Ultraviolet ozone $\left(\mathrm{UV} / \mathrm{O}_{3}\right)$ system was assembled as such the ozone was supplied by NANO Ozone generator (Absolute Ozone, Canada) and UV irradiation by UVC lamp. Pure oxygen were channelled at the follow rate of $0.5 \mathrm{lpm}$ into the ozone generator with $20 \mathrm{psig}$ standard working pressure. The generate ozone was channeled to a Dreschel bottle that contained microcarrier. Dreschel bottle were shaked at $250 \mathrm{rpm}$ on orbital shaker that was placed in the UV box. UV irradiation and ozone aeration were simultaneously activated for 60 minutes to introduce oxygen functional groups [9].

\section{Gelatin Immobilization}

The surface of $\mathrm{UV} / \mathrm{O}_{3}$ treated PCL microcarrier was activated using $1.5 \mu \mathrm{mol} / \mathrm{ml}$ of EDAC and $10 \mathrm{mM}$ of NHS. The activation mixture was incubated at $37{ }^{\circ} \mathrm{C}$ for 24 hours. The microcarrier was then washed with MES buffer prior to gelatin immobilized in $80 \mathrm{mg} / \mathrm{ml}$ gelatin solution and incubated at $37{ }^{\circ} \mathrm{C}$ for 24 hours. Lastly the microcarrier was washed with deionized water using vacuum filtration method and dried in an oven overnight.

\section{E. Characterization}

Analytical techniques were used to magnify, visualize and investigate the distribution elements on the surface of microcarrier by means of scanning electron microscope (SEM) (Hitachi, S3400N) and attenuated total reflectance Fourier transform infrared (ATR-FTIR) spectrometer (Thermo-Scientific, Nicolet iS50).

\section{F. Biological Evaluation}

The porous microcarriers were tested in mammalian suspension cell culture utilizing an established continuous cell line, Vero (ATCC-CCL-81 ${ }^{\text {TM}}$ ). The ability of porous microcarrier to carry cells were compared between microcarrier that was treated with $\mathrm{UV} / \mathrm{O}_{3}$ and microcarrier that was immobilized with gelatin. Two hundred millilitre media were prepared and placed in $500 \mathrm{ml}$ spinner vessel (BellCo, Vineland,NJ, USA). Both porous PCL microcarrier were sterilize using diluted $70 \%$ ethanol solution with overnight incubation. Separation between $70 \%$ ehanol and microcarrier were conducted by allowing the microcarrier to be settled at the bottom by gravity separation. Supernatant were removed and was replaced with PBS and lastly, equilibrated in culture medium (DMEM with $10 \%$ serum). The $0.6 \mathrm{~g}$ microcarriers in DMEM were transferred into spinner vessels. Cell inoculum at concentration of $1.5 \times 10^{5}$ cells/ml was calculated using Neuber heamacytometer as a counting chamber. The prepared inoculum was transferred into spinner flask which contain culture media and strile microcarriers. Growth profile of the Vero cells on both microcarriers were generated through sampling with time interval every 12 hours. Sampling were done by aspirated 2 $\mathrm{ml}$ of cell suspension from spinner flask. One mililiter of cell suspension was placed in 24 well culture plate and the morphology of cell were observed under inverted phase microscope. The remaining $1 \mathrm{ml}$ of the sample were placed in the tube for cell harvesting and calculation.

\section{RESULTS AND DISCUSSION}

\section{A. Microcarrier Properties}

Porous PCL microcarrier was successfully produced using solvent evaporation method.

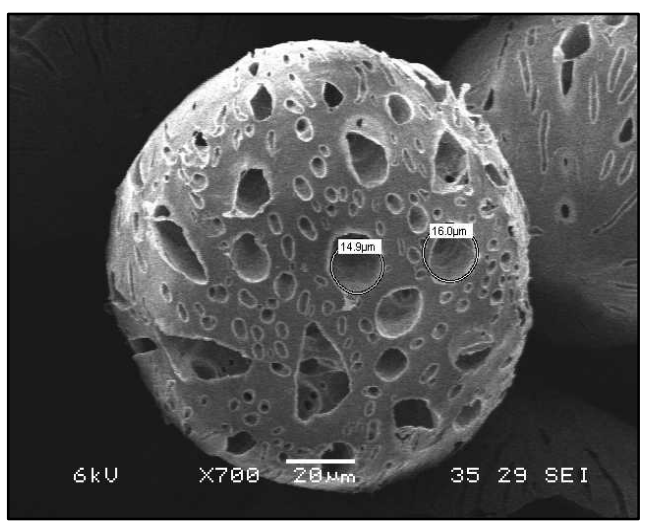

Fig. 1 SEM image of porous PCL microcarrier at $20 \%$ (w/v) camphene 


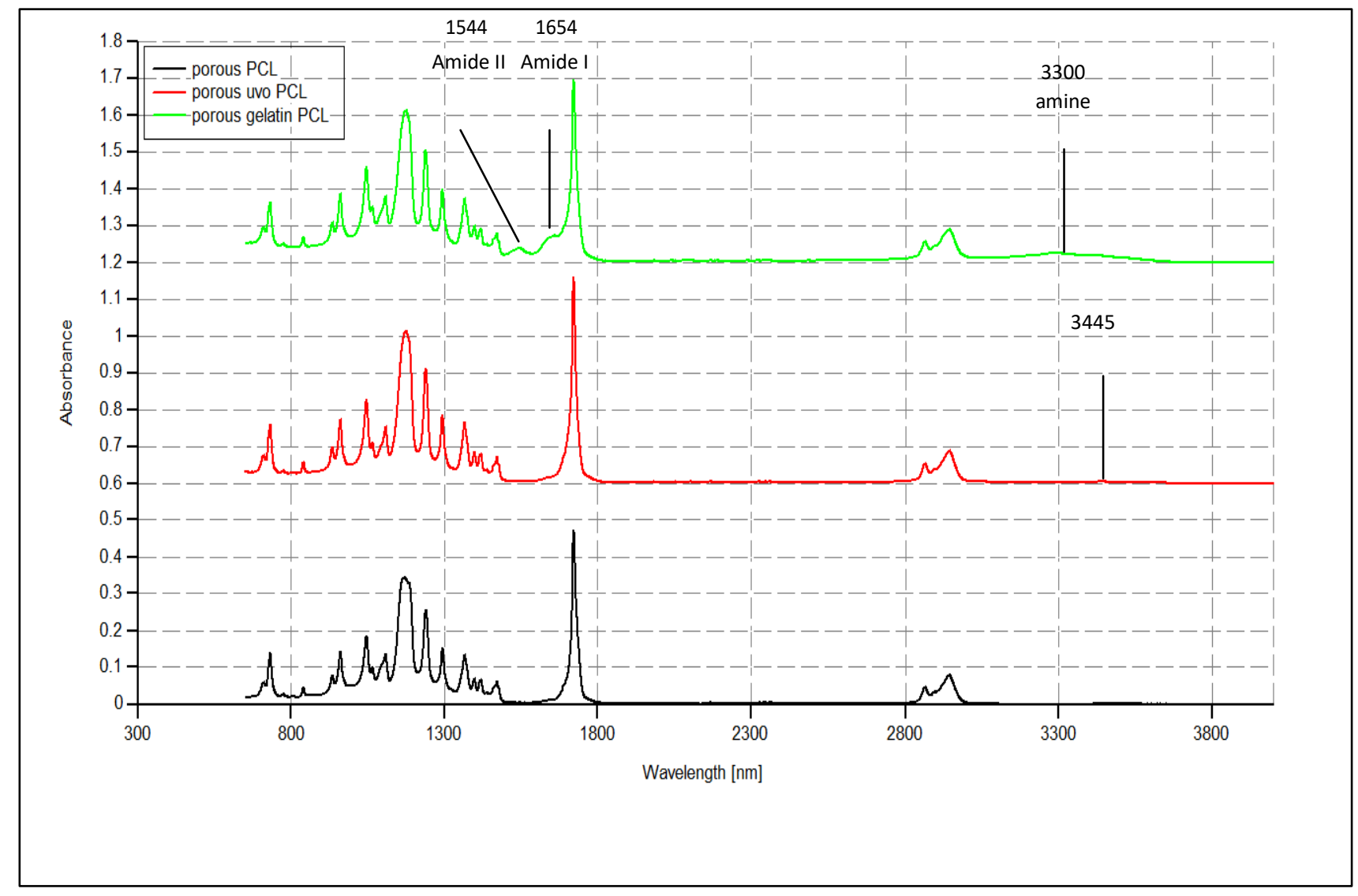

Fig. 2 ATR-FTIR spectra shows the elements content of the untreated PCL (porous PCL), UV/O ${ }_{3}$ treated PCL (porous uvo PCL) and gelatin immobilized porous PCL (porous gelatin PCL).

Fig. 1 shows the scanning electron microscopy image of PCL microcarrier produced at camphene concentration of $20 \%(\mathrm{w} / \mathrm{v})$. The average pore size of the porous microcarrier was approximately $11.74 \pm 8.32 \mu \mathrm{m}$. The presence of pores on the microcarrier was detected by scanning electron microcscopy (SEM) and the average size of pores generated was measured on 5 arbitrarily selected area using image analysis software, Image $\mathrm{J}^{\circledR}$.

The microcarrier was then treated with $\mathrm{UV} / \mathrm{O}_{3}$, which introduced oxygen functional groups (hydroxyl, carbonyl and carboxyl) on the surface of the microcarrier. In the light of $\mathrm{UV} / \mathrm{O}_{3}$ treatment, the combination reaction between $\mathrm{UV}$ irradiation that released energy and ozone aeration produced molecular oxygen and its radical (oxygen atom). The product of the reaction was reacted with the surface of the porous PCL microcarrier[9]. Instead of energy released that favors oxygen degradation, UV irradiation may caused cleavage on the ester linkage of PCL chain. The cleavage contribute to the addition of the oxygen content on the surface of microcarrier and make it more susceptible for gelatin immobilization [10]. The properties of $\mathrm{UV} / \mathrm{O}_{3}$ treated and gelatin immobilized PCL surface were futher characterized to confirm the presence of the functional group and to ensure gelatin was successfully incorporated on the porous PCL microcarrier surface.

FTIR spectra of PCL samples (Fig. 2) show the addition of new peak at $3445 \mathrm{~cm}^{-1}$ for $\mathrm{UV} / \mathrm{O}_{3}$ treated porous PCL sample. This spectrum shows that the $\mathrm{O}-\mathrm{H}$ group has been deposited on the main chain of PCL by oxidation process during ${\mathrm{UV} / \mathrm{O}_{3}}_{3}$ [11]. Meanwhile, the chemical environment around carbonyl group also marked for modification as expension of the range of spectrum from 1600 to $1750 \mathrm{~cm}^{-1}$. The range of spectrum were attributed to the free acids [12].

After the surface treatment of porous PCL microcarrier, gelatin was immobilized using zero length cross-linker reagents, EDAC together with NHS. The immobilization of gelatin on the porous PCL microcarrier was acknowledge by the incidence of spectrum $3300 \mathrm{~cm}^{-1}$ that were attribute to the overlapping spectrum of between amine functional group $(\mathrm{N}-\mathrm{H})$ stretching and hydroxyl group $(\mathrm{O}-\mathrm{H})$. Besides, the presence of spectrum that attribute to the amide I and amide II group were observed at $1654 \mathrm{~cm}^{-1}$ and $1544 \mathrm{~cm}^{-1}$ [13].

\section{B. Biocompatibility of Porous PCL Microcarrier}

The growth of Vero (ATCC-CCL-81 ${ }^{\mathrm{TM}}$ ) cells on different PCL microcarrier surfaces was investigated by suspension culture in stirred spinner flasks. The growth profile of Vero that grow on gelatin immobilize microcarrier and $\mathrm{UV} / \mathrm{O}_{3}$ treated were presented in Fig. 3. Meanwhile, Table I shows the number of maximum cells attached on the microcarrier, growth rate and doubling time of the two different cultures. From the graph, Vero cells started to attach and proliferate well on both porous microcarrier within one day after inoculation. The attached cells continued to grow until it 
reached maximum number of cells of $2.90 \times 10^{5}$ cells $/ \mathrm{ml}$ on day six for gelatin coated porous PCL microcarrier as compared to the maximum cell number of $\mathrm{UV} / \mathrm{O}_{3}$ treated PCL microcarrier which showed the number of cells decreased after day two. The results appear to suggest that the addition of gelatin on the surface of porous microcarrier enhances the biocompatibility of the microcarrier by providing the biological macromolecules support which is favorable for cell attachment and proliferation.

The discrepancy in growth pattern of Vero cell between $\mathrm{UV} / \mathrm{O}_{3}$ treated and gelatin immobilized porous microcarrier could be due to the different properties of microcarrier surface (charge surface; $\mathrm{UV} / \mathrm{O}_{3}$ and biological composition; gelatin coated). Therefore, different serum protein were absorb in the two different properties of microcarrier surface [14]. The charge of the microcarrier surface plays significant role in passive adhesion and repulsion of cell, but equally important in which serum proteins absorbs and coated the entire microcarrier surface [14]. Protein serum can be catagorise in two different major class which are fibrous and globular [15]. The common sequence of Arg-Gly-Asp (RGD) attribute to the universal adhesive site of protein was discovered in fibrous proteins in serum such as vitronectin, growth factor and fibronectin. This promotes the cell attachement and proliferation on the microcarrier surface.

Whereas, the globular proteins which also known as nonadhesive protein in serum act vise versa which inhibit the attachment of cell on the microcarrier surface. These proteins reacted by hinder the expression of the fibrous protein or competing with the fibrous protein to absorb to the polymer surface.

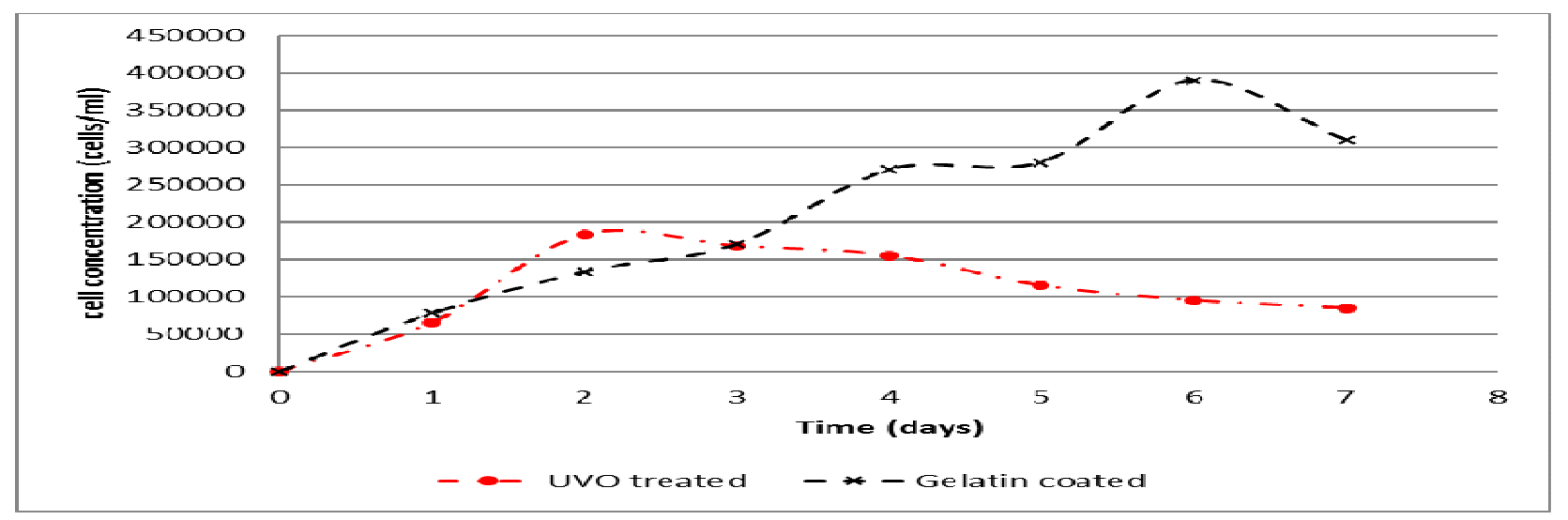

Fig. 3 Growth profile of Vero cells on different porous microcarriers in $500 \mathrm{ml}$ stirred spinner flasks: (x) gelatin coated porous PCL, and $(\bullet) \mathrm{UV} / \mathrm{O}_{3}$ treated porous PCL.

Introduction of functional group (Carboxyl) on the microcarrier surface promotes the difusion of serum protein on the surface of microcarrier thus may enhabce the cell attachment [16]. The electstatic interaction effect combining with the favourable atachement site serve by the serum protein absorption on the microcarrier surface allowed the Vero cells to attach and proliferate onto the $\mathrm{UV} / \mathrm{O}_{3}$ treated microcarrier for the first two days. The cell density was then observed to hardly retain on the microcarrier surface after the second day.

As for gelatin coated porous PCL microcarrier, report from previous study shows that the surface also absorbed serum protein but in low concerntration as compared tot the charge microcarrier surface [14]. Gelatin contain the specific biologically cell attachement properties that make it favourable for Vero cell attachment. Besides, Vero cells were also observed to retain on the microcarrier surface through out the cultivation period.

Each cell has different attachment ligand and adherent force to adhere to one surface. Therefore, it is inaccurate to assume that one type of surface condition such as charge surface or protein coated surface is relevant for culturing all type of cells [17].
TABLE I

VAlues of MaXimum Cell CONCENTRATION, Growth KinEtics AND DOUBLING TIME OF VERO CELLS ON DIFFERENT TYPES OF MICROCARRIER

\begin{tabular}{|c|c|c|c|}
\hline Microcarrier & $\begin{array}{c}\text { Maximum cell } \\
\text { number } \\
\left(\times 10^{5} \text { cells } / \mathrm{ml}\right)\end{array}$ & $\begin{array}{c}\text { Growth rate, } \\
\mu\left(\mathrm{h}^{-1}\right)\end{array}$ & $\begin{array}{c}\text { Doubling time, } \\
\mathrm{td}(\mathrm{h})\end{array}$ \\
\hline $\begin{array}{c}\mathrm{UV} / \mathrm{O}_{3} \\
\text { treated }\end{array}$ & 1.83 & 0.0065 & 106.6 \\
\hline $\begin{array}{c}\text { Gelatin } \\
\text { coated }\end{array}$ & 3.90 & 0.0115 & 60.1 \\
\hline
\end{tabular}

Fig. 4 shows the inverted phase microcarrier image and SEM image for $\mathrm{UV} / \mathrm{O}_{3}$ (Fig. 4a, 4c) and gelatin coated (Fig. $4 \mathrm{~b}, 4 \mathrm{~d})$ respectively. Observation on SEM image on day 2 of cultivation shows that Vero cells were in the second phase of attachment to microcarrier in which the morphology of the attached cells appeared spheroidal. On the other hand for cell culture grown in the presence of gelatin coated porous microcarrier showed that the cells were in their fourth phase where the cells were fully attached and extremely flat. 


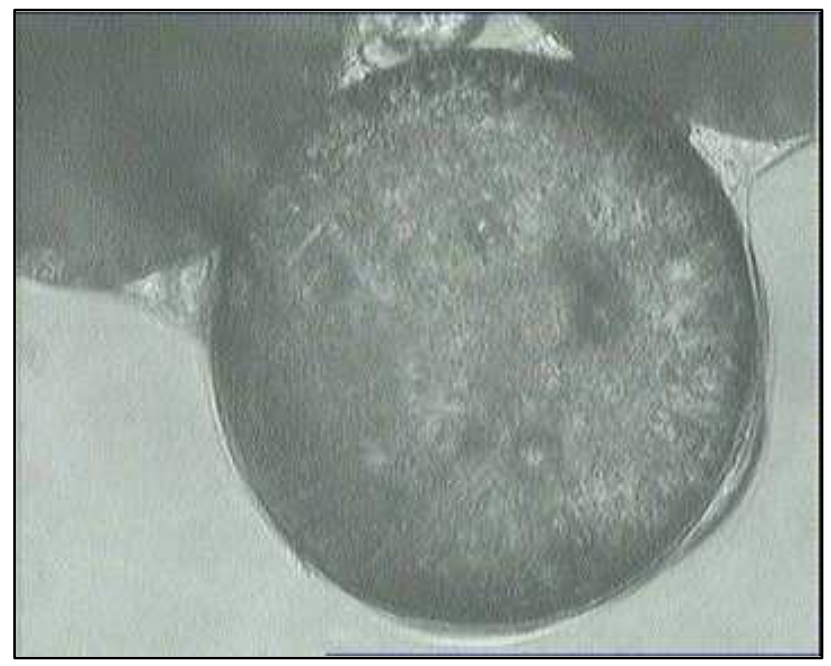

(a)

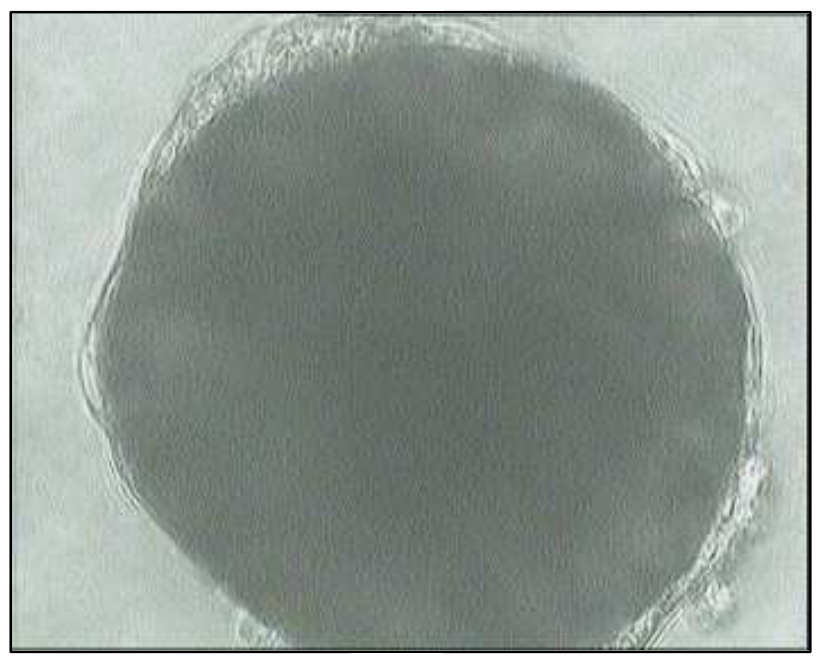

(b)

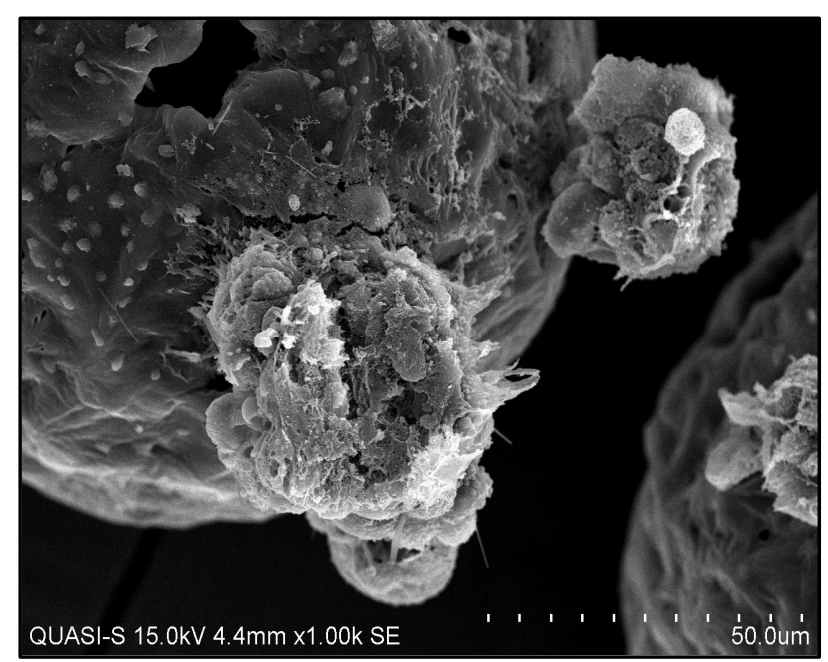

(c)

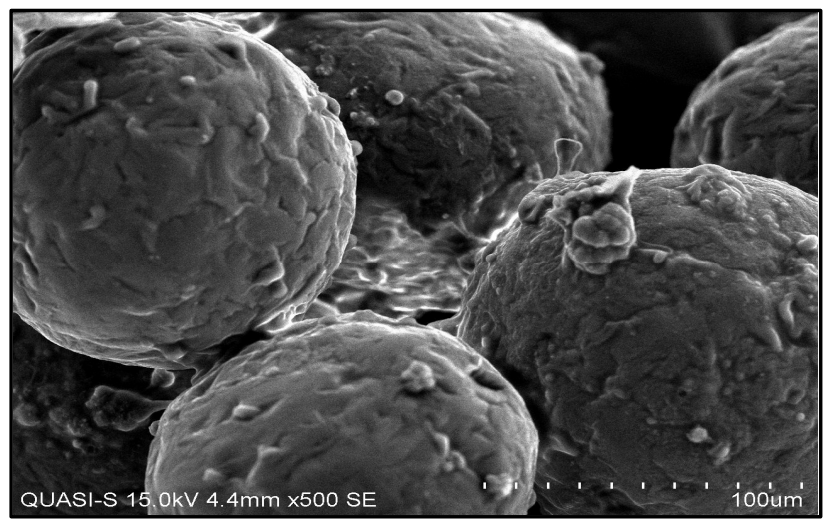

(d)

Fig. 4 Inverted phase microcarrier image for (a) $\mathrm{UV} / \mathrm{O}_{3}$ treated porous microcarrier and (b) gelatin coated porous microcarrier, and SEM image of (c) $\mathrm{UV} / \mathrm{O}_{3}$ treated porous microcarrier and (d) gelatin coated porous microcarrier.

\section{CONCLUSIONS}

Porous PCL microcarrier has been successfully fabricated by introducing camphene as a porogen that generated pore channel in the microcarrier. The presence of oxygen functional group on the surface of microcarrier after the $\mathrm{UV} / \mathrm{O}_{3}$ treatmet as well as the incoporated of gelatin was confirmed by FTIR. The ability of gelatin coated porous PCL microcarriers to support growth and proliferation of cells were assessed using Vero cells and the results strongly suggest that gelatin coated PCL microcarriers were able to support the growth of Vero cells better.

\section{ACKNOWLEDGMENT}

The authors are grateful to Silverline Biologics Sdn. Bhd. for partially funding this study.

\section{REFERENCES}

[1] S. J. Hong, H. S. Yu and H. W. Kim. "Tissue engineering polymeric microcarriers with macroporous morphology and bone-bioactive surface”. Macromol. Biosci., vol. 9, pp. 639-645, 2009.

[2] U. S. Shin, J-H. Park, S-J. Hong, J-E. Yu and W-H. Kim. "Porous biomedical composite microspheres developed for cell delivering scaffold in bone regeneration." Mater. Lette., vol. 64, pp2261-2264, 2010.

[3] Q. Zhang, K. Tan, Z. Ye, Y. Zhang, W. Tan and M. Lang. "Preparation of open porous polycaprolactone microspheres and their applications as effective cell carriers in hydrogel system." Mater. Sci. and Engin.C, vol. 32(8), pp. 2589-2595, 2012

[4] J. Li, A. T-L. Lam, J. P. W. Toh, S. Reuveny, S. K-H. Oh and W. K. Birch. "Tunable volumetric density and porous structure of spherical poly- $\varepsilon$-caprolactone microcarriers, as applied in human mesenchymal stem cell expansion.” Langmuir, vol. 33, pp. 3068-307, 2017.

[5] B. K. Kim, S. J. Hwang, J. B. Park and H. J. Park. "Preparation and characterization of drug-loaded polymethacrylate microspheres by an emulsion solvent evaporation method." J. Microencapsulation, vol 19, pp. 811-22, 2000.

[6] H. Heiskanen, P. Denifl, P. Pitkänen and M. Hurme. "Effect of concentration and temperature on the properties of microspheres prepared using an emulsion-solvent extraction process." Adv. Powder Technology, 23(6), 779-786,2011. 
[7] H. Tan, J. Wu, D. Huang and C. Gao. " The design of biodegradable microcarriers for induces cell aggregation." Macromol Biosci, vol. 10, pp. 156-63, 2010.

[8] M. A Arifin, M. Mel, N. Samsudin, Y. Z. H-Y. Hashim, H. M. Salleh, I. Sopyan and N. Nordin. "Ultra violet/ozone treated polystyrene microcarriers for animal cell culture." J. Chem. Technol. Biotechnol., vol. 91, pp. 2607-2619, 2015.

[9] T. N. Murakami, Y. Fukushima, Y. Hirano, Y. Tokuoka, M. Takahashi and N. Kawashima. "Surface modification of polystyrene and poly (methylmetochrylate) by active oxygen treatment." Appl. Surf. vol. 249, pp. 425-432, 2005.

[10] W. Zhou, G. Ma, and , Z.Su. Microspheres for cell culture. In Ma, G., $\&$ Su, Z. (Ed.). Microcapsules in Biotechnology. New York: Taylor and Francis. 2013.

[11] M. A. Sabino. "Oxidation of polycaprolactone to induce compatibility with other degradable polyester." Poly Degrad and Stab, vol. 92, pp986-996, 2007.
[12] C. Wu. "Fabrication and characterization of chitosan microcarrier for hepatocyte culture." J. Appl. Polym. Sci, vol. 88, pp. 28882895,2002.

[13] Yuan S, Xiong G, Roguin A, \& Choong C. "Immobilization of gelatin on poly(glycidyl methacrylate)- grafted polycaprolactone substrates to improve cell material interactions." Biointerphases, vol. 7, pp. 30, 2012.

[14] B. S. Jacobson, and U. S. Ryan. "Growth of endothelial and HeLa cells on a new multipurpose microcarrier that is positive, negative or collagen coated." Tissue and Cell, vol. 14,pp. 69-83. 1987)

[15] G.E. Healthcare handbook. Microcarrier Cell Culture principle and methods 2005.

[16] D. O. H Teare, N. Emmison C. Ton-That and R. H. Bradley. "Effects of Serum on the Kinetics of CHO Attachment to Ultraviolet-Ozone Modified Polystyrene Surfaces." Journal of Colloid and Interface Science, vol. 234, pp. 84-89, 2001. 